\title{
Práticas de avaliação do professor de Matemática sob a luz do pensamento complexo
}

Tatiana Laiz Freitas da Fonseca Oliveira

Doutoranda pela Pontifícia Universidade Católica do Paraná, Bacharel em Matemática e Física pela Universidade Tuiuti do Paraná (2002), Mestrado em Educação pela Universidade Tuiuti do Paraná (2015),. ORCID: http://orcid.org/0000-0001-9362-9251

E-mail: tatianalaiz@hotmail.com 


\section{Resumo}

Este trabalho apresenta uma investigação sobre metodologias de avaliação da aprendizagem de Matemática, usadas por professores do Ensino Fundamental. Ao longo desse trabalho, analisamos o conceito de avaliação da aprendizagem e a formação do professor de Matemática sob a luz do Pensamento Complexo. Ao discutir práticas avaliativas de aprendizagem de Matemática, percebeu-se que muitos resumem as avaliações a métodos tradicionais. O objetivo deste trabalho estava em analisar as metodologias de avaliação da aprendizagem de Matemática, bem como os constructos desses professores após uma formação sob a luz da complexidade. Este trabalho foi desenvolvido em duas etapas: uma delas consistiu na elaboração de uma formação para os professores de Matemática do Ensino Fundamental da região de Curitiba de várias escolas estaduais, e no segundo momento, foi realizada uma postagem on-line de uma sequência didática partir do entendendo do novo Referencial teórico do Paraná no qual tem como base a BNCC.

Palavras-chave: Palavras-chave: Educação Matemática. Pensamento complexo. Formação de Professores.

\section{Abstract}

This paper presents an investigation on mathematics learning assessment methodologies used by elementary school teachers. Throughout this work we analyze the concept of learning assessment and the formation of the mathematics teacher in the light of the complexity thinking. In discussing evaluative mathematical learning practices, it was noted that many summarize assessments to traditional methods. The objective of this work was to analyze the methodologies of assessment of mathematics learning, as well as the constructs of these teachers after a formation in the light of complexity. This work was developed in two stages: one of them consisted of the elaboration of a formation for the Elementary School Mathematics teachers of the Curitiba region of several state schools and, in the second moment, an online post of a didactic follow-up was made from the understanding of the new Parana's theoretical framework on which the BNCC is based.

Keywords: Mathematical Education. Thinking of complexity. Teacher training. 


\section{Introdução}

O conhecimento profissional, em qualquer área de atuação, representa o conjunto de saberes o qual possibilita o sujeito a exercer sua profissão, por meio de suas práticas pedagógicas, construindo, assim, ao longo de sua jornada profissional a sua identidade docente. Para alguns teóricos como Behrens (2013), Moraes (1997), Petraglia (2001), Freire (1997), Morin (2011, 2015), Kilpatrick (2011), Santos (2009), entre outros, esse conhecimento é construído durante sua formação inicial e aprimorado durante a sua formação continuada ao longo da sua carreira profissional. Esse conhecimento transforma-se em prática pedagógica, a qual deve ser crítica, inovadora e transformadora, assentada em paradigmas emergentes ou inovadores como alternativa para superar a visão clássica da educação, a qual “[...] deve abandonar a concepção predominante no século XIX de mera transmissão do conhecimento [...] que se tornou obsoleta para a educação dos futuros cidadãos em uma sociedade democrática: plural, participativa, solidária, integradora" (IMBERNÓN, 2010, p.7), para que se possa corresponder didaticamente as necessidades educacionais do mundo contemporâneo.

Diante de tantas mudanças que vêm ocorrendo na sociedade na qual vivemos, a reflexão sobre novas práticas pedagógicas se faz necessária, quando se compreende que a sociedade está em constante transformação, ocasionada pela presença exponencial das tecnologias em consonância com a globalização, disseminando a informação de tal modo que o professor não é mais o único detentor do saber. Dessa maneira, não há mais espaço para práticas pedagógicas na quais o papel dos alunos se limita a copiar, decorar, repetir e reproduzir, que, segundo relata Behrens (2013), são pilares que sustentam a ação docente de um paradigma conservador e que nas palavras de Freire (1975, p. 66-68) denominou de educação bancária uma vez que: 
[...] o educador é o sujeito, conduz os educandos à memorização mecânica do conteúdo narrado. Mais ainda, a narração os transforma em vasilhas, em recipientes a serem enchidos pelo educador. [...] Em lugar de comunicar-se, o educador faz comunicados e depósitos, que os educandos, meras incidências, recebem pacientemente, memorizam e repetem. Eis aí a concepção bancária da educação, em que a única margem de ação que se oferece aos educandos é a de receberem os depósitos e arquivá-los.

O paradigma emergente ou inovador utilizado na formação continuada, teve sua base epistemológica fundamentada no pensamento complexo de Edgar Morin que possibilita uma nova maneira de pensar, em oposição ao pensamento que separa, simplifica e reduz a realidade e o conhecimento. A complexidade busca religar os conhecimentos que foram fragmentados, buscando ligar as relações existentes entre as partes e o todo, focalizar as inter-relações sujeito/objeto, pensar o objeto e suas relações, compreender a dinâmica nãolinear presente no conhecimento e na aprendizagem.

\section{Fundamentação Teórica}

\section{A FORMAÇÃO DOCENTE}

A formação docente deve ter como princípio um ensino de qualidade que possibilite o desenvolvimento integral do estudante, para que este tenha um conhecimento que lhe permita ter autonomia, saberes, competências, responsabilidade para exercer seu papel de cidadão planetário, logo, se faz necessário pensar em uma formação docente de qualidade.

Entende-se que é necessário um olhar para a formação inicial, bem como no quando e onde ocorrem as primeiras aproximações com a teoria/prática, seja nos cursos de graduação e ou licenciaturas, que habilitam legalmente para o exercício da docência na educação básica bem como na formação continuada, a 
qual deve ser direcionada para o desenvolvimento e aperfeiçoamento das competências orientadas para a profissionalização docente.

Historicamente, a formação inicial docente na educação superior, na década de 1970, por meio da Pedagogia e ou das Licenciaturas, estava na orientação da Lei de Diretrizes e Bases da Educação, Lei no. 5.692/71, a qual tinha como orientação uma abordagem educacional tecnicista, procedente da corrente positivista, fundamentada pela psicologia behaviorista, influenciando as instituições de ensino formal, entre elas a universidade. $O$ paradigma de formação era pautado na incumbência de ser modeladora do comportamento humano utilizando os treinamentos para garantir a transmissão de conhecimentos, habilidades e atitudes voltados para a racionalidade, a objetividade e a separabilidade.

Na década de 1990, surge a nova LDB -Lei no. 9.694/96, apontando novas orientações para o sistema educacional, bem como sobre a finalidade da formação dos profissionais da educação que deve "atender aos objetivos dos diferentes níveis e modalidades de ensino e às características de cada fase de desenvolvimento do educando", a formação deve possibilitar uma visão especifica sobre os níveis e modalidades de ensino, assim como a especificidade dos alunos de acordo com sua faixa etária. A LDB aponta ainda sobre a importância dessa formação fazer "a associação entre teorias e práticas, inclusive mediante capacitação em serviço" e "o aproveitamento da formação e experiências anteriores", que pode ser da escola ou fora dela.

Nesse período, a orientação didática pedagógica era estruturada na concepção das Teorias Críticas da Educação Brasileira nomeadas de Abordagem Progressista (SAVIANI, 1983), e a Concepção Crítica da Educação (LIBÂNEO, 1995). O desenvolvimento dessas abordagens possibilitou um repensar da prática pedagógica pautada na pedagogia racionalista, fragmentadora e de produtividade do sistema e do trabalho, mas uma prática pedagógica que 
segundo Libâneo (1985, p. 81) o professor pudesse “[...] preparar boas aulas, exercícios, temas de debates, dominar as técnicas didáticas, conhecer o mundo de valores, gostos dos alunos, conhecerem as condições concretas de vida e de trabalho a fim de saber quais as efetivas desvantagens e quais são as positividades dos alunos" e completa afirmando que "ao mesmo tempo, o professor deve estar preparado teoricamente para perceber as contradições da sociedade, os determinantes de classe que direcionam sua atividade prática, o papel do ensino enquanto coadjuvante do movimento histórico de emancipação".

A concepção de formação inicial e ou continuada do docente sempre foi um tema desafiador para os pesquisadores. Na década de 2000, temos novas abordagens, entre elas as contribuições de Zabalza (2004, p. 41-42) que fala em uma "formação formativa", compreendendo como uma forma mais ampla e completa da formação, com foco nos procedimentos didáticos pedagógicos, englobando também o desenvolvimento pessoal, a apropriação de novos conhecimentos culturais, acadêmicos e profissionais, ampliação de habilidades procedimentais específicas e gerais, aumento da sensibilidade dos valores e atitudes de maneira que o docente possa relacionar-se melhor consigo mesmo e com os outros.

Esse posicionamento aponta para uma ampliação das abordagens educacionais vigentes na década de 1990, a busca por pensamentos que possam auxiliar em formações inicias e ou continuadas de maneira que o docente aprenda a desconstruir velhos pensamentos e buscar novos rumos para a prática pedagógica, entendendo que não existe um método a ser seguido, mas um conhecimento a ser lapidado e construído, requerendo e necessitando evitar o pensamento que separa, que desune, vindouro de um pensamento cartesiano que impossibilita olhar a unidade complexa do homem e do conhecimento. 


\section{A PRÁTICA PEDAGÓGICA E O PENSAMENTO COMPLEXO}

Pensar a prática pedagógica, sob a luz da complexidade, é visualizar que a docência possui uma dinâmica na qual os processos são imprevisíveis, inesperados e criativos, permitindo ir além do pensado, do visualizado. Essa dinâmica nos revela a não linearidade no processo da aprendizagem e também na elaboração do conhecimento.

No entendimento de Morin (1999), a complexidade busca o diálogo entre as ciências e as relações entre todos os tipos de pensamento não como um dogma, mas como um desafio a ser enfrentado, pois a complexidade é "[...] o pensamento capaz de reunir complexus: aquilo que é tecido conjuntamente, de contextualizar, de globalizar e também capaz de reconhecer o singular, o individual, o concreto" (MORIN, LE MOGNÉ, 2000, p. 207).

Portanto, a complexidade na perspectiva dialógica permite que o docente compreenda que dois termos antagônicos não são excludentes, mas complementares permitindo que na prática pedagógica possa ocorrer o diálogo com o diferente, com a diversidade, com os opostos. Essa compreensão reconhece o imaginário, a intuição inserida na prática de sala de aula como forma para romper com a divisão entre o racional e o irracional, pois na aprendizagem estes elementos se concluem e se enriquecem reciprocamente.

A prática pedagógica, na perspectiva da complexidade, leva o docente compreender a existência de interações ecossistêmicas, pois o objeto do conhecimento, ou o sistema, precisa ser idealizado de forma relacional, pois está assentado em um determinado contexto do qual é dependente.

Para abdicar de uma docência racional que leva muitas vezes a fragmentação do conhecimento e da aprendizagem é necessário reconhecer que o pensamento complexo nos leva a pensar nas relações, nas conexões e nos vínculos. Isto é reconhecer que a multidimensionalidade do indivíduo, o ser 
humano não tem apenas pensamento e ações racionais, mas também um raciocinar e fazer intuitivo, cognitivo e afetivo.

Os princípios ou operadores cognitivos do Pensamento Complexo proposto por Morin (2000) em parceria com Le Mogné no livro :A inteligência da complexidade são apresentados como conceitos, ferramentas ou categorias do pensamento que podem auxiliar na compreensão da complexidade descortinando outros caminhos e estratégias de ação para colocá-la em prática de maneira a "[...] superar dicotomias cartesianas, a religar teoria e prática, ação política com prática ética, mente e corpo, indivíduo e contexto, saberes científicos e humanísticos, deixando de fragmentar o sujeito" (MORAES, 1997, p. 108).

Tais princípios ou operadores cognitivos para pensar o complexo auxiliam a "pensar bem", como afirma Morin (apud MORAES, 2008, p. 97), pois eles possibilitam novos raciocínios que religam os saberes provenientes do pensamento linear.

\section{A CONSTRUÇÃO DA FORMAÇÃO}

Participaram da construção desse processo no total de 106 professores de Ensino Fundamental de Matemática, da região de Curitiba. Tratou-se de uma pesquisa com abordagem qualitativa do tipo pesquisa-ação. Foram propostas para tanto, na primeira fase, uma formação presencial com cinco perguntas para cada grupo dos professores relacionadas ao estudo do Referencial curricular do Paraná, sob a luz do Paradigma da complexidade. Essa dinâmica foi denominada de rotação por estação, conhecida como uma metodologia ativa, conforme descrevemos nas figuras 1e 2 abaixo. 
Figura 1 - Produção final dos professores. Figura 2 - Professores produzindo.

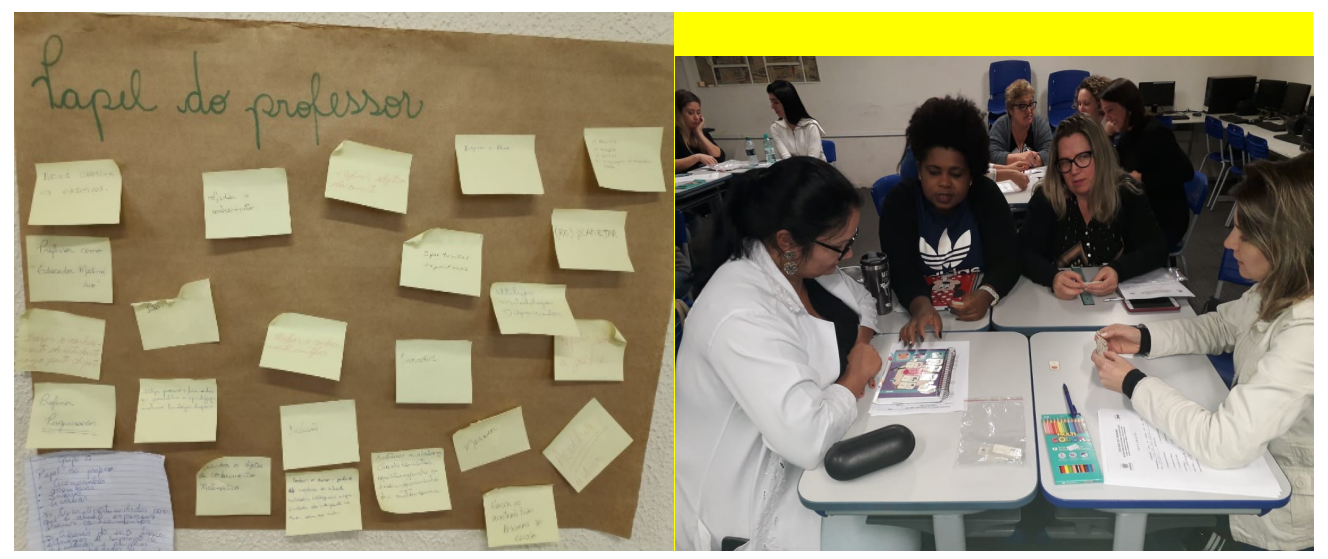

Fonte: Produção particular.

Fonte: Produção particular.

Nas metodologias ativas o professor é considerado o orquestrador da construção do conhecimento, mediador, articulador crítico e criativo do processo pedagógico, produtor de seu próprio conhecimento; incentiva o aluno a aprender a aprender "instigando-o", centrando sua competência estimuladora no ensino com pesquisa, orienta os alunos a se expressarem de maneira fundamentada, exercitando a dúvida através do questionamento.

O professor ultrapassa as barreiras de mero instrutor, construindo um caminho de dupla autonomia entre aluno e professor, tornando-se protagonista junto ao aluno na produção do conhecimento, através de uma aliança na qual aluno e professor são parceiros nesse trabalho coletivo. Essa metodologia busca a produção do conhecimento pelos alunos e professores, com autonomia, criatividade e criticidade; prioriza a inseparabilidade do ensino com pesquisa, ultrapassando o ensino livresco e tradicional no qual se baseia a aulas meramente expositivas, com a finalidade de reprodução do conhecimento.

Para a segunda fase, realizamos um levantamento de todas as respostas dos professores e, para este artigo, faremos uma análise sobre o processo de avaliação após as postagens on-line de uma sequência didática, esta seria a segunda tarefa dos professores para concluírem a formação. 
Esse grande compartilhamento de ideias, subsidiou as discussões que propiciaram a construção de uma pesquisa como a proposição de uma formação a partir dos constructos dos professores para uma prática pedagógica emergente que vem abrir caminhos para a superação da visão conservadora, dicotómica da reprodução do conhecimento.

\section{A FALA DOS PROFESSORES: CAMINHOS A SEREM TRILHADOS}

Como mapa conceitual abaixo podemos tirar algumas conclusões a respeito do entendimento do professor quanto ao processo de construção de avaliação soba luz do Paradigma da complexidade e o referencial curricular do Paraná. Para podermos entender melhor o processo de rotação, foi desenhado um mapa conceitual, denominado de Imagem 3, com as respostas dos professores. Para este artigo, como já havíamos mencionado, falaremos apenas dos constructos com respeito ao processo de avaliação, na sequência do mapa conceitual deixamos os pontos de interrogação para darmos sequência nas análises em futuras pesquisas.

Figura 3 - fluxograma formação

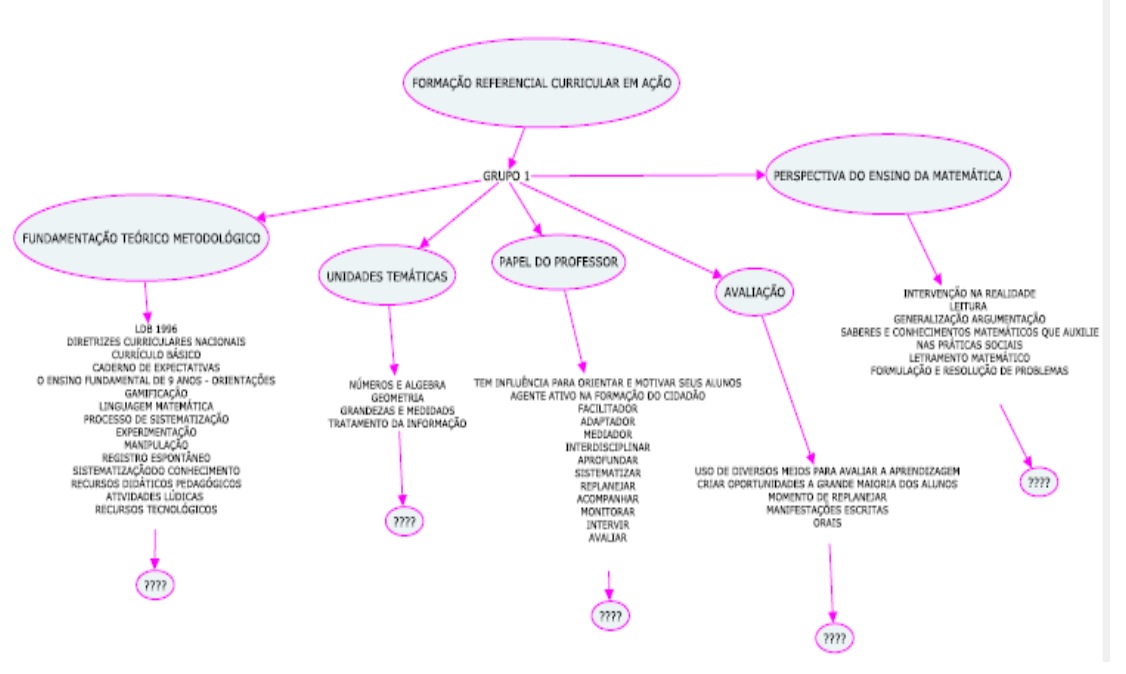

Fonte: Produção particular. 


\section{Considerações Finais}

\section{COMEÇANDO O TRILHAR}

A abordagem progressista, no processo de avaliação, segundo Moraes (1997), o professor tem o papel de garantir o movimento, o fluxo de energia, a riqueza o processo, através da manutenção do diálogo, propondo situações problemas, desafios, propondo reflexões, estabelecendo conexões, ponte entre os conhecimentos adquiridos e os novos conceitos, entre o ocorrido e o pretendido. Ainda para essa autora, o professor respeita os alunos e acredita serem capazes de construir sua própria história, a fazer escolhas e trilhar caminhos críticos, reflexivos e criativos.

Portanto, o professor progressista é também sujeito do processo, estabelece uma relação horizontal com o aluno, buscando, através do diálogo, a sua fonte empreendedora na construção do conhecimento. O docente não impõe suas ideias, procura estar ao lado do aluno superando uma visão de aluno objeto e não sujeito, nega a forma de autoritarismo, repressão possibilitando uma convivência harmoniosa entre os pares. Por ter mais experiência acerca das realidades sociais, procura ser o mediador, a ponte entre o saber elaborado e o conhecimento a ser produzido. Para Mizukami (1986) o docente procura durante uma abordagem progressista, procura desmistificar e questionar uma cultura dominante, criando condições de uma reflexão por parte dos alunos com relação ao seu contexto social e assim criar condições de análise e questionamentos próprios.

Segundo o relado dos professores, nessa primeira formação, para a avalição após a formação, com um olhar mais humano e progressista, sob a visão do paradigma da complexidade, é necessário que os professores tenham mais formações que o ajudem a usar práticas que venham a proporcionar ao sujeito 
aprendiz a construir seu processo de aprendizagem a sua autonomia com oportunidades de metodologias a partir da escrita e oralidade, tão importante e esquecida no ensino da matemática.

\section{Referências}

BEHRENS, M. A. Paradigma da complexidade: metodologia de projetos, contratos didáticos e portfólios. Petrópolis: Vozes, 2006.

BEHRENS, M. A. O Paradigma emergente e a prática pedagógica. Petrópolis: Vozes, 2013.

FERNANDES, J. V. Saberes, competências, valores e afetos necessários ao bom desempenho profissional do/a professor/a. Lisboa: Plátano Edições Técnicas, 2001.

FREIRE, P. Pedagogia da autonomia. Rio de Janeiro: Paz e Terra, 1997.

FREIRE, P. Pedagogia da esperança. Rio de Janeiro: Paz e Terra, 1992.

MIZUKAMI, M. G. N. Ensino: as abordagens do processo. São Paulo: EPU, 1986.

MORAES, M. C. O paradigma educacional emergente. Campinas: Papirus, 1997.

MORAES, M. C. Pensamento ecossistêmico - Educação, aprendizagem e cidadania no século XXI. Petrópolis: Vozes, 2004.

MORIN, E. Sete saberes necessários à educação do futuro. São Paulo: Cortez; Brasília, DF: Unesco, 2011.

MORIN, E. Cabeça bem-feita. Rio de Janeiro: Bertrand Brasil, 2015. 
NEVES, J. L. Pesquisa Qualitativa: Característica, usos e possibilidades.

Caderno de Pesquisa em Administração, São Paulo, vol. 1, n.3, 1996.

SILVA, S. A. I. Valores em educação. Petrópolis: Vozes, 1986.

SAVIANI, D. Escola e Democracia. 6. Ed. São Paulo: Cortez, 1985.

TARDIF, M. Saberes docentes e formação profissional. Petrópolis: Vozes, 2007.

ZEICHNER, K. M. A formação reflexiva de professores: Ideias e práticas. Lisboa: Educa. 